\section{(2) OPEN ACCESS}

\title{
Complex regional pain syndrome and bone marrow oedema syndrome: family ties potentially closer than expected
}

\author{
Samy Benchouk (D) , ${ }^{1}$ Pierre-Alain Buchard, ${ }^{2}$ François Luthi (iD) ${ }^{3,4}$
}

\begin{abstract}
${ }^{1}$ Department for Musculoskeletal Rehabilitation, Clinique Romande de Réadaptation, Sion, Switzerland

${ }^{2}$ Department of Rheumatology, Clinique Romande de Réadaptation, Sion, Switzerland ${ }^{3}$ Department of Medical Research, Clinique romande de readaptation, Sion, VS, Switzerland

${ }^{4}$ Department of Physical Medicine and Rehabilitation, Orthopaedic Hospital, Lausanne University Hospital, Lausanne, Switzerland
\end{abstract}

\section{Correspondence to} Dr Samy Benchouk; samy.benchouk@gmail.com

Accepted 22 July 2020

\section{Check for updates}

(c) BMJ Publishing Group Limited 2020. Re-use permitted under CC BY-NC. No commercial re-use. See rights and permissions. Published by BMJ.

To cite: Benchouk $S$, Buchard P-A, Luthi F. BMJ Case Rep 2020;13:e234600. doi:10.1136/bcr-2020234600

\section{SUMMARY}

Complex regional pain syndrome (CRPS) and bone marrow edema syndrome (BMES) are two rare conditions that are still being discussed. They are generally considered as two distinct entities, yet they share similarities such as a homogeneous bone marrow edema is also often found in the early phase of CRPS. We present the case of a 41-year-old man with CRPS after a foot fracture followed by the development of painful BMES of the ipsilateral knee and hip a few weeks later. The search for another pathology was negative. After pamidronate infusions, the evolution was spectacular: the disappearance of hip pain at 1 month and more than $50 \%$ reduction in knee and foot pain at 2 months. At final follow-up (1 year), the patient was asymptomatic. This case reinforces the idea of a possible link between CRPS and BMES probably through similar trabecular bone involvement. Imaging remains useful in diagnosis of CRPS.

\section{BACKGROUND}

Complex regional pain syndrome (CRPS) and bone marrow edema syndrome (BMES) are two rare entities whose physiopathology and treatment remain debated. CRPS is considered as a disabling condition that progresses to chronicity (more than 1 year) in about one-third of cases, ${ }^{1-3}$ while BMES is considered to be a painful self-limiting condition with spontaneous resolution in 4-24 months. ${ }^{4}$ Over the years, the CRPS diagnostic criteria have evolved towards purely clinical criteria (the so-called Budapest criteria) ${ }^{5}$ and any reference to deep bone involvement with osteopenia revealed by radiology, as already shown by Paul Sudeck a century ago, has been removed. ${ }^{6}$ On the other hand, the diagnosis of BMES may be suspected clinically (pain and progressive functional impairment) but requires imaging confirmation (MRI). ${ }^{7}$ Although generally considered to be separate entities, links are suspected between them, particularly because of similar bone involvements also often documented in the early phase of CRPS. In addition, both syndromes may occur in multifocal and migrant forms. ${ }^{8} 9$ Except for the Steinbrocker's syndrome (or shoulder-arm syndrome), however multifocal or migrant forms remain scarce. Bisphosphonates (BPs), a classical treatment for many bone disorders, can also be effective in both situations (CRPS, BMES). ${ }^{10} 11$ However, it is unusual to find them together in the same individual a few weeks apart. The case depicted here has the particularity of sequentially combining both entities in a short period of time (weeks): first a CRPS of the foot with a diffuse bone marrow edema and then multifocal BMES of the knee and the hip in the ipsilateral side. Curiously, after BPs administration, the clinical recovery and disappearance of the bone marrow edema went the other way in a few months: first the hip (clinical recovery at 1 month and disappearance of bone marrow edema at 3 months), then the knee (clinical recovery at 2 months and disappearance of bone marrow edema at 3 months) and finally the foot (1 year), where it all began.

\section{CASE PRESENTATION}

A 41-year-old winegrower, a smoker, moderately overweight but without any other known comorbidity, fell at work. A left navicular fracture of the foot was diagnosed and conservatively treated with a VACOped for over 7 weeks. After immobilisation, the foot remained painful, swollen and hot, while the healing of the fracture was considered to be favourable. After 3 months, a CRPS was suspected and the orthopaedic surgeon started a calcitonin treatment for 6 weeks. Because of the inefficacy of this treatment and the severe pain and functional impairment, the patient was referred to the rehabilitation service. CRPS diagnosis was confirmed according to the following criteria: continuing pain disproportionate to the initiating event, foot hyperesthesia, skin colour (more red) and temperature

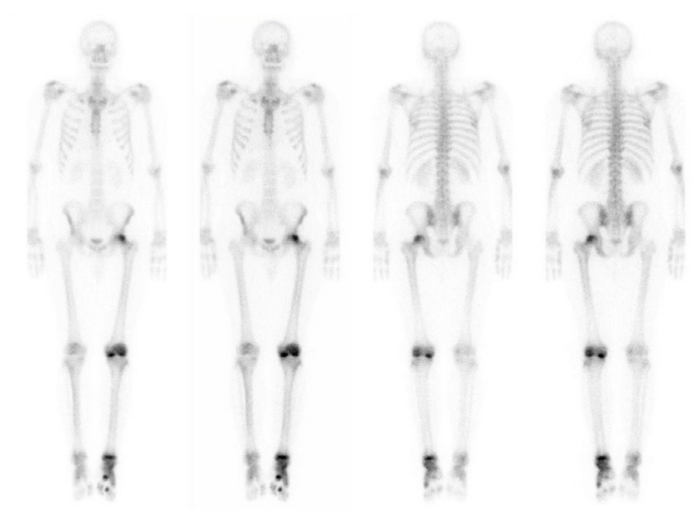

Figure 1 The bone scintigraphy, late-bone phase, showing uptake of the tracers to the three sites concerned: hip, knee and foot. 

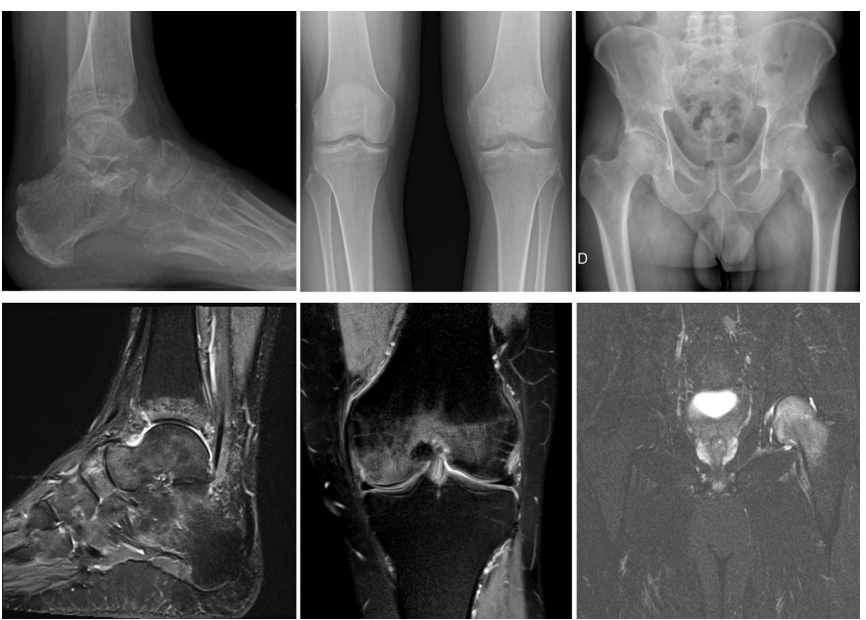

Figure 2 Upper part: standard X-ray showing diffuse osteopenia of the ankle, knee and hip. Lower part: the MRI showed a diffuse, homogeneous T2 hypersignal, without clear delimitation or cartilage damage, of the ankle and tarsal bones, femoral condyles, and head and neck of the femur.

asymmetry $\left(2.7^{\circ} \mathrm{C}\right.$ with infrared thermometer $)$, hyperhidrosis, edema ( $2 \mathrm{~cm}$ larger), stiffness and weakness of the foot and ankle (positive Budapest criteria). The patient continued to move with crutches without loading his foot. During this first consultation, the patient also mentioned that he had felt knee pain on the same side for a few weeks. There were no other painful locations. Apart from diffuse amyotrophy of the lower limb and painful percussion of knee bones with fingers, the physical examination was normal. A three-phase Tc99 bone scintigraphy (BS) was ordered for two reasons: first, to confirm that this scan was positive at the three phases, which seems to be a good predictor of therapeutic response to $\mathrm{BPs}^{12}$; second, to screen for possible bone damage to the knee, osteonecrosis or multifocal CRPS. Ten days later, the patient was called to discuss the results of the BS and treatment options. During the consultation, he incidentally announced that he was suffering from the left hip.

\section{INVESTIGATIONS}

BS showed an increased uptake of the tracers in the left foot across the three phases (capillarity permeability, hyperemia and osteoblastic activity). For the left knee and hip, only the scintigraphic

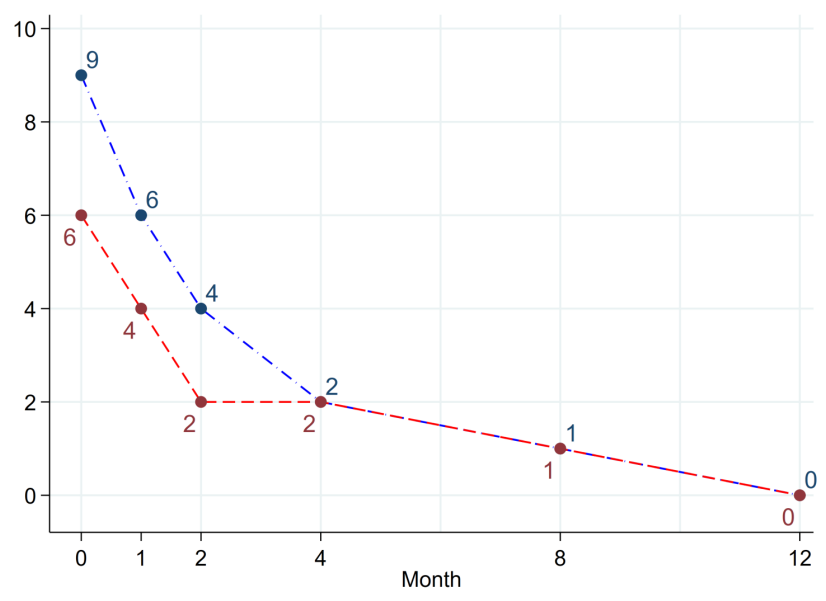

Figure 3 Evolution of the Brief Pain Inventory interference (blue) and severity (red) subscales over time. late-bone phase was available and showed bone hyperfixation of the knee condyles and femoral head (figure 1). MRIs of the foot, knee and hip were requested to clarify the nature of the scintigraphic images. This further investigation showed a diffuse, homogeneous T1 hyposignal and T2 hypersignal of the ankle and tarsal bones, femoral condyles, and the head and neck of the femur, without clear delimitation or cartilage damage (figure 2, lower part). Standard X-ray examination showed diffuse osteopenia affecting the ankle, knee and hip (figure 2, upper part). Blood tests showed no inflammatory syndrome, no disturbance of phosphocalcic metabolism, no argument in favour of increased bone turnover and dual-energy X-ray absorptiometry was also normal reasonably excluding bone fragility. The only abnormalities were hyperlipidaemia and moderately disturbed liver tests (Aspartate Aminotransferase (ASAT) 67, GammaGlutamyl Transferase (GGT) 233), which are compatible with excess weight and regular alcohol consumption (winegrower), but without any signs of dependence (normal Carbohydrate Deficient Transferrin (CDT)). A thoraco-abdominal scan was normal.

\section{DIFFERENTIAL DIAGNOSIS}

Multifocal bone scintigraphic images opened up a broad differential diagnosis: osteonecrosis, stress fractures, inflammatory rheumatism, infections, metastases. However, MRI images were typical of BMES (homogeneous bone edema, hyposignal in T1, hypersignal in T2 with blurred contours, no clear limits and no associated cartilage lesions) and also typical of an early form of CRPS. ${ }^{13}$ In particular, they reasonably excluded osteonecrosis (even if in early forms, the initial image can be very similar), stress fractures and metastases. The other examinations excluded other differential diagnoses in an otherwise healthy patient. The final diagnosis was foot and ankle CRPS, combined with BMES of the knee and hip. The whole clinical presentation can also be interpreted as a migrant multifocal form of CRPS.

\section{TREATMENT}

Pamidronate infusions $(90 \mathrm{mg}$ ) were administered four times: J1, J2, J8 and J9, with vitamino-calcic substitution (to prevent hypocalcaemia). ${ }^{14} 15$ Treatment was well tolerated with only myalgia during a few days. The patient continued his analgesic (paracetamol) and non-steroidal anti-inflammatory drugs (ibuprofen) treatment. After the infusions, no physiotherapy was required. The patient did exercises at home and used a Compex instrument (electromyostimulation) that he had bought himself.

\section{OUTCOME AND FOLLOW-UP}

Clinically, the pain assessment measured with the Brief Pain Inventory Questionnaire ${ }^{16}$ showed a dramatic positive trend, both in the severity and in the interference pain scales. After 1 month, hip pain had completely disappeared and knee and foot pain had markedly decreased. After 2 months, the knee pain disappeared and the foot pain on the numeric rating scale was reduced by more than $50 \%$ (see figure 3 ). Gradually, the patient abandoned his crutches (3 months), stopped medication and was able to return to work, first at $50 \%$, then without any restrictions. Radiologically, the BMES of the hip and knee completely disappeared after 3 months, while the BMES of the foot had decreased significantly. After 1 year, there was no trace of bone marrow edema of the foot on MRI. 


\section{DISCUSSION}

This case report highlights two key points. First, CRPS and BMES are generally considered as separate entities. However, this case shows that they share at least an important common feature, namely the involvement of the trabecular bone that almost cannot be distinguished between the two conditions ${ }^{4}$, even if in CRPS, the T2 and Short-TI Inversion Recovery (STIR) increased marrow signal is quite less homogeneous. This is perfectly illustrated here, the patient having the two entities developed at a few weeks' interval only. Second, and contrary to the prevailing opinion, ${ }^{6}$ this case report also suggests that imaging remains an important part of the diagnosis and management of CRPS. Deep-bone damage revealed by radiology, as already shown by Paul Sudeck a century ago ${ }^{17} 18$ is evident here. In CRPS, deep bone involvement is not rare. Recent studies combining BS and the Budapest criteria have found between $24 \%$ and $80 \%$ positive BS. ${ }^{19} 20$ A shorter duration of disease and a higher proportion of men being associated with a higher proportion of positive BS. ${ }^{21}$ Imaging is probably not mandatory for the diagnosis of all cases of CRPS, although they may be useful to improve sensitivity and for the diagnosis of partial ${ }^{20}$ or incomplete forms $\mathrm{s}^{22}$ and to determine if deep joints, as hips, are implicated or not. ${ }^{23}$

From the physiopathological point of view, in both syndromes, bone insult is not characterised by an increased osteoclastic activity. Rather, it is vascular phenomena that would be at work with a diffuse increased blood flow, vascular permeability that induces plasma exudation, acidosis, local tissue hypoxia, promoting hydroxyapatite chemical dissolution. Vascular phenomena would explain the increased tracer uptake in the early phases of BS, while late hyperfixation would be explained by the increase in available binding sites due to the reduction of hydroxyapatite crystals. ${ }^{24}$ The efficacy of BPs infusions is also another common feature of both syndromes. ${ }^{41425}$ The action mechanisms involved are still unclear but probably multifactorial. Among them, the ability of BPs to reduce the dissolution of hydroxyapatite crystals secondary to hypoxia and local acidosis is proposed. Their plausible ability to limit the release of proinflammatory cytokines

\section{Patient's perspective}

I was very unsettled by the evolution of my pain, which started in my foot and gradually referred to my hip. However, I was reassured by the explanations when the final diagnosis was made. Being able to see the images to visibly and concretely illustrate my ailments also helped me to understand and accept my illness. It was very rewarding to 'see' the damage disappear as it happened. In addition, I was struck by the effectiveness of the treatment.

\section{Learning points}

- Complex regional pain syndrome (CRPS) and bone marrow edema syndrome (BMES) share common characteristics, of which the trabecular bone seems to be the common denominator.

- Although no longer included in the diagnostic reference criteria, imaging is still of interest in the evaluation of CRPS.

- Bisphosphonates deserve to be considered quickly in both syndromes, especially in cases of severe pain/disability.

- CRPS and BMES must remain exclusion diagnoses, selected after a rigorous diagnostic process. and neuropeptides involved in the painful sensation (substance P, nerve growth factor, calcitonin gene-related peptide) is another possible way ${ }^{26}$ with encouraging reports in clinical conditions but also in an animal model of CRPS. ${ }^{27}$ The most convincing efficacy obtained with BPs was with neridronate, ${ }^{14}$ which is not available in Switzerland. We therefore chose to use pamidronate in a bioequivalent dosage. This dosage is high, even higher than that administered in moderate forms of Paget's disease. Lower dosages have been associated with lower efficacy or failure in the treatment of CRPS. ${ }^{14}$ Clinicians should therefore be aware that if they prescribe BPs, they should prescribe adequate dosages and avoid oral forms. It seems important to obtain a sufficient dose of medication in the area of interest in a short period of time. The confirmation of bone marrow edema should therefore motivate early use of BPs, especially when the pain and disability are severe. A retrospective analysis of predictors of responsiveness to BPs treatment in the presence of CRPS suggests that patients who respond to this treatment have a shorter duration of illness than non-responders. ${ }^{12}$ An OR of 0.83 could be measured for each additional month. In other words, each additional month reduces the odds of a favourable outcome. The faster recovery of the most recent insults here (first the hip, then the knee, finally the foot) could perhaps be explained in this way.

In conclusion, although not considered as identical syndromes to date, CRPS and BMES share common bone imagery, physiopathology, and therapeutic response to BPs. Imagery remains useful in the diagnosis of CRPS. Further studies of the mechanisms involved in bone damage could advance both understanding and treatment of these two intriguing syndromes.

Contributors Planning: SB, FL. Conduct: SB, FL. Reporting: SB, P-AB, FL. Conception and design: $\mathrm{SB}, \mathrm{P}-\mathrm{AB}, \mathrm{FL}$. Acquisition of data: $\mathrm{SB}$, FL. Interpretation of data: SB, P-AB, FL. Writing — original draft: SB, FL. Writing—review and editing: SB, $P-A B, F L$.

Funding The authors have not declared a specific grant for this research from any funding agency in the public, commercial or not-for-profit sectors.

Competing interests None declared.

Patient consent for publication Obtained.

Provenance and peer review Not commissioned; externally peer reviewed.

Open access This is an open access article distributed in accordance with the Creative Commons Attribution Non Commercial (CC BY-NC 4.0) license, which permits others to distribute, remix, adapt, build upon this work non-commercially, and license their derivative works on different terms, provided the original work is properly cited and the use is non-commercial. See: http://creativecommons.org/ licenses/by-nc/4.0/.

\section{ORCID iDs}

Samy Benchouk http://orcid.org/0000-0003-3052-5791

François Luthi http://orcid.org/0000-0002-7440-1523

\section{REFERENCES}

1 Bean DJ, Johnson MH, Heiss-Dunlop W, et al. Extent of recovery in the first 12 months of complex regional pain syndrome type-1: A prospective study. Eur J Pain 2016;20:884-94.

2 Bean DJ, Johnson MH, Kydd RR. The outcome of complex regional pain syndrome type 1: a systematic review. J Pain 2014;15:677-90

3 Scholz-Odermatt SM, Luthi F, Wertli MM, et al. Direct health care cost and work incapacity related to complex regional pain syndrome in Switzerland: a retrospective analysis from 2008 to 2015. Pain Med 2019;20:1559-69.

4 Manara M, Varenna M. A clinical overview of bone marrow edema. Reumatismo 2014;66:184-96.

5 Harden RN, Bruehl S, Perez RSGM, et al. Validation of proposed diagnostic criteria (the "Budapest Criteria") for Complex Regional Pain Syndrome. Pain 2010;150:268-74.

6 Stanton-Hicks Michael d'A, Stanton-Hicks MD. Crps: what's in a name? taxonomy, epidemiology, neurologic, immune and autoimmune considerations. Reg Anesth Pain Med 2019:44:376-87.

7 Mirghasemi SA, Trepman E, Sadeghi MS, et al. Bone marrow edema syndrome in the foot and ankle. Foot Ankle Int 2016;37:1364-73. 
8 Cahir JG, Toms AP. Regional migratory osteoporosis. Eur J Radiol 2008:67:2-10.

9 Maleki J, LeBel AA, Bennett GJ, et al. Patterns of spread in complex regional pain syndrome, type I (reflex sympathetic dystrophy). Pain 2000;88:259-66.

10 Wertli MM, Kessels AGH, Perez RSGM, et al. Rational pain management in complex regional pain syndrome 1 (CRPS 1)--a network meta-analysis. Pain Med 2014;15:1575-89.

11 Eriksen EF. Treatment of bone marrow lesions (bone marrow edema). Bonekey Rep 2015;4:755.

12 Varenna M, Manara M, Rovelli F, et al. Predictors of responsiveness to bisphosphonate treatment in patients with complex regional pain syndrome type I: a retrospective chart analysis. Pain Med 2017;18:1131-8.

13 Bonadio MB, Filho AGO, Helito CP, et al. Bone marrow lesion: image, clinical presentation, and treatment. Magn Reson Insights 2017;10:338.

14 Varenna M, Adami S, Rossini M, et al. Treatment of complex regional pain syndrome type I with neridronate: a randomized, double-blind, placebo-controlled study. Rheumatology 2013;52:534-42.

15 Varenna M, Zucchi F, Binelli L, et al. Intravenous pamidronate in the treatment of transient osteoporosis of the hip. Bone 2002;31:96-101.

16 Stanhope J. Brief pain inventory review. Occup Med 2016;66:496-7.

17 Sudeck P. Ueber die akute (trophoneurotische) Knochenatrophie nach Entzündungen und Traumen der Extremitäten). Dtsch med Wochenschr 1902;28:336-8.

18 Sudeck P. Uber die akute entzundliche Knochenatrophie. Arch Klin Chir 1900;62:147-56.
19 Moon JY, Park SY, Kim YC, et al. Analysis of patterns of three-phase bone scintigraphy for patients with complex regional pain syndrome diagnosed using the proposed research criteria (the 'Budapest Criteria'). Br J Anaesth 2012;108:655-61.

20 Konzelmann M, Deriaz O, Luthi F. Diagnosis of partial complex regional pain syndrome type 1 of the hand: retrospective study of 16 cases and literature review. BMC Neurol 2013;13:28.

21 Wertli MM, Brunner F, Steurer J, et al. Usefulness of bone scintigraphy for the diagnosis of complex regional pain syndrome 1: a systematic review and Bayesian meta-analysis. PLoS One 2017;12:e0173688.

22 Giannotti S, Bottai V, Dell'Osso G, et al. Algodystrophy: complex regional pain syndrome and incomplete forms. Clin Cases Miner Bone Metab 2016;13:11-14.

23 Asadipooya K, Graves L, Greene LW. Transient osteoporosis of the hip: review of the literature. Osteoporos Int 2017;28:1805-16.

24 Varenna M, Crotti C. Bisphosphonates in the treatment of complex regional pain syndrome: is bone the main player at early stage of the disease? Rheumatol Int 2018;38:1959-62.

25 Giusti A, Bianchi G. Treatment of complex regional pain syndrome type I with bisphosphonates. RMD Open 2015;1:e000056.

26 Varenna M. Bisphosphonates beyond their anti-osteoclastic properties. Rheumatology 2014;53:965-7.

27 Wang L, Guo T-Z, Hou S, et al. Bisphosphonates inhibit pain, bone loss, and inflammation in a rat tibia fracture model of complex regional pain syndrome. Anesth Analg 2016;123:1033-45.

Copyright 2020 BMJ Publishing Group. All rights reserved. For permission to reuse any of this content visit https://www.bmj.com/company/products-services/rights-and-licensing/permissions/

BMJ Case Report Fellows may re-use this article for personal use and teaching without any further permission.

Become a Fellow of BMJ Case Reports today and you can:

- Submit as many cases as you like

- Enjoy fast sympathetic peer review and rapid publication of accepted articles

- Access all the published articles

Re-use any of the published material for personal use and teaching without further permission

Customer Service

If you have any further queries about your subscription, please contact our customer services team on +44 (0) 2071111105 or via email at support@bmj.com.

Visit casereports.bmj.com for more articles like this and to become a Fellow 